\title{
UN CASO DE IMPERSONALIDAD SEMÁNTICA: EL USO DE LOS LLAMADOS SINGULARES ARBITRARIOS EN CORPORA ORALES
}

\author{
Elisa Barrajón López \\ Universidad de Alicante \\ Elisa.Barrajon@ua.es
}

\section{Resumen}

Este trabajo se centra en el análisis de varios ejemplos de segunda persona del singular como casos de impersonalidad semántica que aparecen en el lenguaje coloquial. Nuestro objetivo es demostrar que la sola presencia de esa segunda persona del singular no es suficiente para provocar la generalización referencial que caracteriza a este tipo de construcciones, sino que deben considerarse diversos factores sintácticos y operadores discursivos si queremos obtener una interpretación universal de estas estructuras.

PALABRAS CLAVE: impersonalidad, encubrimiento, generalización, operadores, modalidad.

\begin{abstract}
This paper deals with the analysis of several instances of singular second person as cases of semantics impersonality appearing in colloquial language. Our purpose is to show that the only presence of that singular second person is not enough in order to provoke the referential generalization which characterizes this type of constructions, but various syntax factors and speech operators should be considered if we desire to obtain a universal reading of this structures.
\end{abstract}

KEY WORDS: impersonality, hiding, generalization, operators, modality.

\section{Introducción}

En ocasiones, especialmente en el lenguaje coloquial, la desinencia verbal de segunda persona del singular no remite a un oyente concreto, sino que más bien alude a un conjunto de individuos que comparten unas mismas circunstancias. Estos casos no responden a una impersonalidad gramatical o sintáctica, puesto que el verbo nos informa de la presencia de un sujeto léxico que puede estar explícito o implícito y que es el pronombre de segunda persona singular $t u ́$, aunque ese tú no siempre hace referencia a un receptor determinado, sino que su referencialidad se ve diluida hasta el punto de recibir una interpretación indefinida o genérica, con lo que estaríamos ante un caso de impersonalidad semántica.

Dado que este uso de la segunda persona del singular sin referente definido se desarrolla especialmente en el ámbito del lenguaje coloquial, pretendemos dar cuenta en lo que sigue, no sólo de dicho uso y de sus características sintáctico-semánticas, sino también de las causas que provocan la pérdida del sentido literal de la segunda persona en favor de una lectura no referencial y, por ello, más totalizadora o universal, partiendo de dos corpora orales: el Corpus oral de la variedad juvenil universitaria del español hablado en Alicañte y el ALCORE (Alicante Corpus del Español)'.

Esta obra se enmarca dentro del proyecto ALCORE, subvencionado por el Ministerio de Educación y Cultura (PB98-0967) y coordinado por la Dr. Dolores Azorín Fernández. Tiene como principal objetivo la plasmación en un corpus del estado actual de la lengua oral utilizada en la ciudad de Alicante. 
De esa manera, comprobaremos que en la impersonalidad semántica de segunda persona del singular pueden intervenir otros factores, fundamentalmente, de naturaleza aspectual y temporal, acompañados a su vez de otros elementos sintácticos como marcadores de generalidad.

\section{Caracterización semántica de la segunda persona del singular}

El verdadero interés que ofrecen los llamados singulares arbitrarios -en términos de $\mathrm{M}^{\mathrm{a}}$ Lluïsa Hernanz (1990a: 153) — es su doble posibilidad de interpretación, debido a que pueden ser entendidos como símbolos de la genericidad y universalidad, pero, al mismo tiempo, pueden llegar a convertirse en encubridores del yo. Para saber si el referente de la segunda persona es generalizado o no, debemos recurrir a dos aspectos pragmáticos fundamentales: el contexto y la situación. A pesar de que en lo sucesivo adoptaremos como herramienta metodológica la diferenciación de los dos valores del tú (genérico y encubridor del yo) para ilustrarlos con mayor claridad, debemos advertir, sin embargo, que ambos valores no pueden deslindarse, dado que siempre se dan conjuntamente.

Por lo que respecta a la lectura universal del pronombre de segunda persona, debemos matizar el hecho de que para que tenga lugar una interpretación genérica no es necesaria la presencia del pronombre $t u ́$, sino que este puede aparecer o no, sin que, por ello, se bloquee el sentido generalizador:

(1) $409<H 5>$ : [...] para él es normal, el problema de las drogas es que al principio las tomas porque te gustan un poquito, porque te sientes bien, y acabas al final tomándolas porque las necesitas para estar normal <silencio>. Ese es el problema de las drogas (Azorín y Jiménez, 1999: 147).

En este ejemplo, la referencia de la segunda persona del singular (tomas, sientes, acabas, necesitas) es generalizadora, universal. No se vincula a un oyente en particular, sino que alude a una generalidad de individuos y a su relación con las drogas, entre los que puede encontrarse, como veremos más adelante, el yo hablante.

$\mathrm{M}^{\mathrm{a}}$ Lluïsa Hernanz, en este sentido, afirma que el aspecto más relevante en la caracterización semántica de los singulares arbitrarios es, precisamente, su versatilidad. Este carácter versátil viene dado por la posible combinación de valores genéricos, tendentes o próximos a la cuantificación universal y valores encubridores, esto es, la identificación del yo con el tú en una misma estructura:

(2) $\langle$ Chu6,M,2,Su,EE,E>: De todas maneras $</$ simultáneo $>$, también pienso yo que a veces a los jóvenes se les $<$ pausa $></$ pausa $><$ repetición $>$ se les $</$ repetición $>$ planteaunas $<$ pausa $></$ pausa $><$ repetición $>$ unas $</$ repetición $>$ metas $<$ fático $><1$ fático $><$ pausa $></$ pausa $>$ a conseguir, que si no consigues esas $<$ sic $>$ mesas $</$ sic $>$, metas, es como si fueras un, <repetición $>$ un $<$ repetición $>$ fracasa $<(d)>0$, ¿no? [...] (ALCORE, pág. 210).

Prueba de esa genericidad que estamos comentando, es que la estructura de segunda persona puede, en ocasiones, parafrasearse por construcciones en las que también se produce una indeterminación del agente: la pasiva refleja o la impersonal semántica cuyo sujeto 
sintáctico es el pronombre indefinido uno: que si no se consiguen esas metas; que si uno no consigue esas metas, es como si fuera un fracasado.

Asimismo, podríamos parafrasear esta estructura por otra cuyo sujeto fuera la primera persona del plural: que si no conseguimos esas metas, es como si fuéramos unos fracasados. Este hecho pone de manifiesto que los singulares arbitrarios no son construcciones neutras con respecto a la inclusión del hablante, dado que siempre nos permiten identificar al sujeto hablante con la colectividad de individuos a los que remite ese tú arreferencial.

Otro aspecto a tener en cuenta, como prueba de la genericidad que caracteriza a estas construcciones, es la posible coexistencia en una misma oración de una pasiva refleja con una impersonal semántica de segunda persona:

(3) $401<$ EI $>$ : Es como considerarlo como, como (-->) el tabaco o como (-->) el alcohol. $O$ sea, que eso se consume y no te engancha $n i$ $n a<(d)\rangle\langle(a)\rangle$ (Azorín y Jiménez, 1999: 121).

Por otra parte, ese sentido universal o encubridor no se limita únicamente a la presencia de la desinencia verbal o del pronombre de segunda persona, sino que se extiende a otros elementos -algunos de ellos ya nos han aparecido en ejemplos anteriores - con contenido de segunda persona, como el pronombre objeto te, el pronombre contigo o adjetivos posesivos:

(4) $318<H 4>$ : Es una... es una disciplina, sobre todo, <vacilación > la literaria, la literaria que... lo más... lo más importante es que te hace reflexionar, o sea, te crea momentos intimos en los que tú reflexionas; entonces (-->) <vacilación $>t<$ palabra cortada $>$.. ya por el simple hecho de leer te cuestionas preguntas, te cuestionas... te cuestionas $<$ vacilación $\rangle$... metas, principios, fines, o sea, te hace $\langle$ sic $\rangle$ una activida $\langle(d)\rangle \ldots$ una activida $\langle(d)>$ que te hace pensar y te hace... y te hace recapacitar <vacilación> solucionar tus... tus dudas (-->),... que siempre las tendrás, y crearte más, es algo, es una especie de... de... es... es... algo (-->).. [...] (Azorín y Jiménez, 1999: 71).

(5) $459<H 4>$ : Ahi estoy muy de acuerdo... Yo por lo menos sí, o sea, no te metes con nadie que es lo que yo intento y vamos.

$460<H 3>$ : ... La mayor <palabra cortada>, la mayoría de la gente, ¿eh?, no toda. $461<H 2>$ : Y que nadie se meta contigo (Azorín y Jiménez, 1999: 251).

Como comentábamos anteriormente, en el uso de la segunda persona del singular, debemos resaltar su carácter inclusivo con respecto al sujeto hablante, es decir, el emisor aparece difuminado en esa generalidad junto con el conjunto de individuos a los que hace referencia ese tú genérico ${ }^{2}$ :

(6) $\langle$ Chu6, M, 2,Su,EE,E $\rangle$ : De todas maneras $</$ simultáneo $\rangle$, también pienso yo que a veces a los jóvenes se les $<$ pausa $></$ pausa $><$ repetición $>$ se les $</$ repetición $>$ plantea unas $<$ pausa $></$ pausa $><$ repetición $>$ unas $</$ repetición $>$ metas $<$ fático $></$ fático $>$

2 Queremos recordar, sin embargo, que este fenómeno lingüístico no es exclusivo del lenguaje coloquial. En narrativa, el escritor se sirve en numerosas ocasiones de la segunda persona, dotando de mayor objetividad al discurso literario. 
$<$ pausa $></$ pausa $>$ a conseguir, que si no consigues esas $<$ sic $>$ mesas $</$ sic $>$, metas, es como si fueras un, <repetición $>$ un $<$ repetición $>$ fracasa $<(d)>0$, ¿no? [...] (ALCO$R E$, pág. 210).

En este ejemplo, extraído del $A L C O R E$, vemos cómo el sujeto hablante se incluye en un conjunto de individuos muy concreto: los jóvenes, al que el interlocutor hace referencia en el discurso, haciendo uso de la segunda persona mediante las formas verbales consigues o fueras. Lo mismo ocurre en este ejemplo del Corpus juvenil en el que el hablante se lamenta de no tener mucho tiempo para ver a sus amigos y se oculta bajo el pronombre te cuando comenta que la verdadera causa de esa falta de tiempo es su carrera o sus estudios:

(7) $41<H 1>$ : Si, si, si, si, sí, tengo amigos de instituto, claro, gran parte de ellos están aquí, sobre todo los importantes, están aqui conmigo, pero tengo otros que por ejemplo están estudiando <nombre propio > Formación Profesional <inombre propio >, ¿no?, entonces pues, sí, sigo la relación con ellos, menos porque <vacilación> la uni <palabra cortada> la facultad te absorbe mucho, no, entonces te queda menos tiempo para dedicarte a esta gente pero en cuanto puedo estoy con ellos, claro [...] (Azorín y Jiménez, 1999: 52).

Un indicio de ese uso inclusivo que presenta el pronombre de segunda persona con respecto al yo hablante, es la posible coaparición en un mismo enunciado de la primera persona (singular o plural) y de la segunda persona del singular:

(8) $341<$ E2>: Es que yo lo que pienso es que (-->)... por lo que yo veo que (-->)... por ejemplo, yo me llevo bien con mi madre y todo esto pero $(-->)$.. que, normalmente cuando tienes un problema o lo que sea, que no sueles recurrir a los padres... y todo esto (Azorín y Jiménez, 1999: 72).

(9) $441<H 1>$ : Pues nada, eso, yo pienso que si construyes un mundo no habria clases sociales pero que las hay, y ya está, y que tanto clases sociales como (-->) no igualda $<(d)>$ de oportunidades ni como eso, o sea, ahora a mi me gusta mucho un ($->)$, un anuncio que están haciendo sobre deficientes, sobre ciegos, y tal, una campaña pues eso, o sea, que yo pienso que eso que si que ocurre, pues me parece que muy bien que haya una concienciación o que al menos haya algo que te lleve a pensar eso, por qué somos distintos o por qué somos iguales (Azorín y Jiménez, 1999: 98).

Este uso inclusivo separa los singulares arbitrarios de las construcciones de tercera persona del singular de carácter impersonal:

(10) $208<H 4>$ : [...] por mucho que dicen que <estilo indirecto $>$ wan a dar soluciones a los temas, y o cada vez se ven menos soluciones </estilo indirecto> por ejemplo en el tema del paro (-->)... [...] (Azorín y Jiménez, 1999: 230).

A pesar de que en este tipo de construcciones podemos observar una indeterminación del agente, en ningún momento se incluye en dicho agente indeterminado el sujeto hablante. Así, mientras que estas construcciones admiten la paráfrasis por una oración cuyo sujeto sea el indefinido alguien (Alguien [no yo] dice que alguien va a dar soluciones...); las de segunda persona, en cambio, no presentan esa posibilidad. Por otro lado, los singulares arbitrarios 
sí pueden admitir como sujeto de la oración, el sintagma nominal genérico la gente, aunque de ello no puede deducirse que la segunda persona y el sintagma la gente sean sinónimos. El sintagma nominal la gente, a diferencia del pronombre tú, no tiene la capacidad de incluir bajo su extensión significativa al emisor.

Asimismo, su carácter inclusivo con respecto al emisor les confiere un status marcado frente a las construcciones pasivo reflejas e impersonales con se, ya que en estas construcciones no puede apreciarse la exclusión o inclusión del sujeto hablante dentro del agente indefinido que las caracteriza. Por el contrario, las construcciones de segunda persona del singular se distinguen por no excluir al emisor o hablante, con lo que ese yo encubierto siempre es tenido en cuenta dentro de esa referencialidad indefinida y será en todo momento el contexto y la situación los que nos aclaren a quién se está refiriendo esa segunda persona.

Como Hidalgo Navarro (1996: 164) señala, una de las características del lenguaje coloquial es el egocentrismo del emisor. Sin embargo, el emisor parece reducir de una forma consciente su protagonismo a través de estas estructuras, dotando al enunciado de una dimensión genérica. Así, si bien existen casos en los que la segunda persona puede interpretarse como un sintagma nominal indefinido de carácter genérico, también en esos mismos casos el $t u ́$ tiende a identificarse con el protagonista de la enunciación. Se trata, por tanto, de un yo encubierto que puede incluso coaparecer, como hemos visto unas líneas más arriba, con la segunda persona del singular.

$\mathrm{M}^{\mathrm{a}}$ Lluïsa Hernanz considera el uso de los singulares arbitrarios en tanto que encubridores del yo como una "estrategia pragmática" de la que el hablante se sirve para ocultarse a sí mismo o para "eludir responsabilidades". El emisor se encubre a sí mismo mediante una referencia generalizadora que le incluye a él y al conjunto de individuos que se encuentran en su misma situación o que comparten unas circunstancias o vivencias semejantes:

\section{(11) $\langle$ Chu $8, H, 2, M e, E E, E\rangle$ : [...] Que $\langle$ pausa $\rangle\langle$ pausa $\rangle \quad\langle$ fätico $\rangle\langle/$ fático $\rangle$ es que} hay una sociedad de consumo. Que, <repetición $>$ que $<$ /repetición $>$ ya desde, $<$ repetición>desde</repetición > nano estás. Yo veo a mi hijo, <repetición >a mi hijo <irepetición $>$, a Angelito. Si no se $<$ palabra cortada $>$ po $<$ palabra cortada $\rangle$, si no le compras unas Nike no se las pone. Y tiene que ser Nike (ALCORE, pág. 210).

Este ejemplo del $A L C O R E$ recoge la opinión de una madre que sufre las consecuencias de vivir en una sociedad consumista, en la que la televisión ejerce una notable influencia en los gustos de los más jóvenes a la hora de comprase unas zapatillas de deporte. Esta madre, responsable del enunciado, consigue mitigar su personalidad haciendo uso de la segunda persona del singular. Con las formas personales estás o compras se oculta a sí misma, pero, al mismo tiempo, se identifica con todas aquellas madres que se enfrentan al mismo problema cuando le compran unas zapatillas a sus hijos. En opinión de Vicente Mateu (1994: 103), estaríamos, concretamente, ante una estrategia desfocalizadora que, partiendo de una serie de recursos gramaticales como la impersonalización, supone un distanciamiento del hablante con respecto al enunciado, con lo que la relación de subjetividad existente entre el enunciador y el enunciado se resiente ${ }^{3}$.

3 Con ello, el discurso puede ser contemplado al mismo tiempo de un modo objetivo (representado por esa actitud de distanciamiento del enunciado por parte del locutor) y subjetivo (el sujeto de la enunciación sigue proyectándose, aunque mitigado, hacia el enunciado). El sujeto del enunciado no soy sólo yo, eres tú y todos los que se encuentren en nuestras mismas circunstancias. 
En este sentido, como comenta Antonio Briz (1998: 84-85), el hablante puede maximizarse o minimizarse de acuerdo con el objetivo que persiga en su intercambio comunicativo. Se produciría un desplazamiento deíctico del yo al tú del que el locutor se sirve para proteger su imagen y atenuar así su papel como responsable de la enunciación.

Por otro lado, E. Lorenzo (1989: 233), justifica el uso del pronombre tú a partir de una hiperutilización de dicho pronombre, debida, en parte, a la gran cantidad de funciones y valores que ha ido adquiriendo, como es el empleo de $t u ́$ como expresión impersonal en el lenguaje coloquial. Este hecho aparece igualmente ligado a una tendencia al tuteo en detrimento de la forma de cortesía tú.

No queremos concluir este apartado, sin hacer referencia a un tipo de construcciones que muestran un comportamiento semejante al tú impersonal. Nos referimos a aquellas estructuras que tienen como sujeto léxico el pronombre indefinido uno/a. En estas construcciones tampoco podemos hablar de una impersonalidad sintáctica, dado que, como resulta evidente, existe un sujeto sintáctico expreso. Sin embargo, sí que responden a un caso de impersonalidad semántica debido a que en ellas aparecen los mismos valores generalizadores y encubridores que hemos examinado a través del uso de la segunda persona del singular:

(12) $373<$ H2>: Hombre, la juventud (-->)... si se droga, ahora mismo... o sea, yo pienso que sabe lo que hace, no es porque, por desconocimiento de un tema... y bueno, antes a lo mejor, cada uno se drogaba, y uno se drogaba porque no tenia nada que hacer, nada mejor que hacer y <onomatopéyico> bun <lonomatopéyico> y se pinchaba $<$ risas $>$. Y resolvia sus problemas, con una jeringuilla $<$ ruido $\rangle<$ risas $\rangle\langle$ simultáneo>. También, eso también <ininteligible> (Azorín y Jiménez, 1999: 145).

(13) $<$ Chu6,M,2,Su,EE,E>: Hombre, porque uno siempre pretende darle a $<$ pausa $></$ pausa $><$ repetición $>a</$ repetición $>$ su hijo<interrupción $></$ interrupción $>$ cree $<$ pausa $></$ pausa $><$ ininteligible $><$ ininteligible $>$ que a lo mejor $<$ ininteligible $><1$ ininteligible $>$ feliz. Que, <repetición $>$ que, que</repetición $>$ no. Igual no aciertas, ¿no? Igual no aciertas (ALCORE, pág. 212).

En el primer caso, el interlocutor está comparando la actitud de los jóvenes ante las drogas con la que podrían tener otras personas pertenecientes a otras generaciones. La forma uno, por tanto, no alude a un solo individuo, sino a un conjunto de seres que responden a un comportamiento común. No obstante, en el segundo ejemplo, se incide en el tema de la educación y en qué hacer para acertar en la labor educativa que desarrollan los padres. Después de escuchar a esa madre de la que hablábamos anteriormente, el interlocutor se solidariza con ella encubriéndose mediante el indefinido uno e identificándose con todo aquel grupo de individuos que, como él, son padres y quieren lo mejor para sus hijos, con lo que, como vemos, el valor genérico y el valor encubridor se entremezclan. De hecho, en esta intervención encontramos el uso de la segunda persona aciertas, con lo que podemos colegir que tanto el indefinido como la desinencia de segunda persona actúan, bien como encubridores pragmáticos, bien como símbolos de genericidad.

No obstante, no debemos olvidar que no basta solamente con la presencia de la segunda persona del singular con su correspondiente pronombre explícito o implícito para expresar un contenido universal o encubridor: 
(14) $4<$ E2>: ¿En qué filología estudias?

$5<H I>$ : Hispánica, como te he dicho antes (Azorín y Jiménez, 1999: 49-50).

(15) $125<$ E1>: ¿Todos pensáis igual? o (-->)... hay alg <palabra cortada > hay alguien que difiera. Tú, por ejemplo, que dices que no (Azorín y Jiménez, 1999: 57).

En estos ejemplos, no encontramos ningún indicio de genericidad o de encubrimiento pragmático debido al contexto y a la situación comunicativa de la que partimos, con lo que parece lógico pensar que además de la presencia de la segunda persona, son necesarios otros elementos lingüísticos para que se produzca esa lectura tan peculiar de tú. Este aspecto será el que desarrollaremos en el siguiente apartado.

\section{Los llamados "inductores de la genericidad"}

Ma Lluïsa Hernanz considera que los singulares arbitrarios no constituyen un fenómeno exclusivamente pragmático, sino que "obedecen a pautas sintácticas regulares" (Hernanz, 1990a: 160). Esto supone la existencia en el entorno oracional de la segunda persona del singular de ciertos "operadores genéricos" que neutralizan el valor referencial de la segunda persona y que son los verdaderos responsables de su valor universal. De ahí que la autora defienda su hipótesis de que los singulares arbitrarios se comportan como una auténtica variable ligada a dichos operadores.

El primer "activador genérico" es, fundamentalmente, el sistema aspectual. Si en todo momento estamos enfatizando el valor generalizador que puede adoptar el pronombre de segunda persona, parece claro que el contexto en el que se desarrolla este uso tan peculiar de $t u ́$ debe ser igualmente genérico. El tiempo verbal por excelencia en todas las afirmaciones de carácter universal es el presente, que da lugar a los conocidos "enunciados gnómicos". Asimismo, el aspecto verbal no debe aludir a un momento temporal concreto, por lo que, será, preferentemente, imperfectivo. Esa falta de referencia temporal influye, indudablemente, en la pérdida del sentido literal que presenta la segunda persona y la dota de una lectura globalizadora:

(16) $409<H 3>$ : Pero, es que una vez que lo has probado, tú no sabes si te vas a enganchar o no, ¿siempre sabes que vas a controlar? Es que eso no es así <simultáneo>. No (-->), aunque sea la... (Azorín y Jiménez, 1999: 121).

(17) $107<H 2>$ : Hombre, siempre es bueno creer en algo... es que (-->) icreencia religiosa?... crees en algo y ya está, no tiene porqué ser religioso (Azorín y Jiménez, 1999: 110).

De ahí que Hernanz atribuya a estas construcciones un carácter "defectivo", porque carecen de una referencia temporal definida. El tiempo y el aspecto se comportarían como una especie de operadores oracionales que ejercen su influencia sobre aquellos elementos que se sitúan dentro de su ámbito oracional. El hablante considera su enunciado como válido en cualquier momento temporal, ya sea este presente, pasado o futuro.

No obstante, el uso exclusivo del presente, sin tener en cuenta ningún elemento más, es insuficiente para crear un contexto genérico que motive la interpretación universal de la segunda persona: 
(18) $15<$ El>: ¿Tienes </simultáneo > hermanos (-->)...? (Azorín y Jiménez, 1999: 257).

Según Hernanz, se requiere, además, la presencia de ciertos "operadores genéricos" que también tienen la propiedad de fijar e "inmovilizar" la temporalidad de la oración, eliminando toda posibilidad de referirse a un punto temporal concreto, ya sea del pasado, del presente o del futuro. Entre estos "transmisores o vehículos de la generidad" - como los denominan Fernández Soriano y Táboas Baylín (Fernández y Táboas, 1999: 1735)--, debemos señalar la clase semántica del verbo, ciertos elementos de carácter adverbial y determinadas estructuras sintácticas con valor condicional.

Por lo que respecta a la clase semántica verbal, son los verbos modales vinculados a las nociones de posibilidad (poder) y necesidad (deber, tener que) los que claramente favorecen la interpretación totalizadora en las construcciones con singulares arbitrarios. Estos verbos sitúan los acontecimientos denotados por los predicados en otros momentos de la enunciación, con lo que la acción designada por el verbo puede tener lugar en otros "mundos posibles" (Fernández y Táboas, 1999: 1736):

(19) $\langle$ PI4,H,3,Me,EI,E $>$ : Nosotros hemos ido a Valencia y hemos estado en Valencia hace muy poco y allí todo el mundo hablaba castellano; no hay nadie que hable en $<$ ininteligible ></ininteligible> te tienes que ir a Alzira, te tienes que ir a yo que sé (ALCORE, pág. 793).

(20) $208<H 4>$ : Lo hace, lo hace mucha gente </simultáneo>, sobre todo al llegar en verano la <vacilación $>$... <nombre propio $>$ San Juan $<$ nombre propio $>$... y todo $\langle(s)>$ estos sitios $<$ fático $=d u d a>$ te, te vendes; o sea, tienes que estar trabajando nueve, diez, once horas al dia y te <simultáneo > dan cuarenta mil (Azorín y Jiménez, 1999: 64).

(21) $265<H 4>$ : [...] Ellos te (-->)... son... han pasa<(d)>o ya por, por tus años y tienen mucha, mucha, mucha escuela ya. Entonces, ya más o menos, te ven, te ven la tendencia o lo que tú puedes hacer bien y lo que no puedes hacer bien [...] (Azorín y Jiménez, 1999: 66).

(22) $466<H 7>$ : Es la barre <palabra cortada $>$... es la barrera más efectiva, pero no tienes una total segurida $\langle(d)>$, entonces tú a tu pareja le puedes decir que si, que $(->)$ siempre que has tenido relaciones sexuales... <fático = duda> has usado el preservativo, pero nadie te dice (-->)... que ese preservativo no (->), no estuviese mal, que no estuviese en (-->) buenas condiciones o que estuviese con una (-->)... microperforación.. [...]. (Azorín y Jiménez, 1999: 128).

Incluso estos mismos predicados y otros de semántica similar, pueden aparecer formando parte de estructuras pronominales que presentan también una impersonalidad semántica - recordemos que este aspecto ya lo habíamos señalado cuando estábamos comentando el valor genérico que presenta la segunda persona--:

(23) $\langle B I, H, 1, M e, E I, E>$ : Imágenes $<$ ininteligible $><$ /ininteligible $></$ simultáneo $>$ y en cambio se adora que no es que se debe adorar, se debe venerar, una cosa es venerar y otra es <repetición>es </repetición> adorar ¿comprendes? pero claro, como 
de <repetición>de</repetición> pequeños: "vamos a adorar al niño, vamos a esto", que te han metido (ALCORE, pág. 1086).

(24) $318<E 2>$ : [...] o sea, para entrar a policía, como él no quiere ser simplemente policia que dice que <estilo indirecto $>$ quiere ser $\langle$ ruido $>$ militar, bueno, o sea, o jefe de $(->) \ldots$ <lestilo indirecto $><$ lestilo indirecto $>$ ¿cómo son? capitán o algo de esto, no sé cómo se llama <ininteligible> no me acuerdo, bueno un grado más superior que un simple policia se necesita una carrera y entras (Azorín y Jiménez, 1999: 92).

Los constituyentes de tipo adverbial que favorecen la interpretación arbitraria de la segunda persona, aportan al núcleo verbal diversas nociones relativas al tiempo, al lugar o al modo. La misión de estos constituyentes, es, fundamentalmente, ubicar la oración en un marco temporal indeterminado y de significación genérica. La arbitrariedad semántica se da especialmente cuando estos elementos se desplazan en la oración, ocupando una posición marcada respecto a su lugar habitual, es decir, cuando se dislocan a la izquierda. Estos constituyentes adverbiales atienden a realizaciones sintácticas muy diversas. Pueden ser sintagmas adverbiales, preposicionales o incluso sintagmas nominales con contenido adverbial:

(25) $428<H 7>$ : [...] Aunque tủ (-->)... aunque te hayan dicho que no sale rentable, porque no vas a ganar tanto dinero como si trabajases aqui en $<$ nombre propio $>$ Espa$\tilde{n} a<$ <nombre propio $>$... siempre vas a ganar más dinero que si no estás trabajando. $Y$ los enfermeros españoles y más los de <nombre propio> Alicante <inombre propio >, son los que más están $<$ fático $=$ duda> pedidos a nivel $(-->)$, no tanto europeo, sino que ya gente viene de (-->) <nombre propio $>$ Estados Unidos </nombre propio > $y$ de bastantes paises a pedir (-->)... gente de aqui. [...] Puedes meterte si quieres a hacer prácticas (-->)... <vacilación>... a hacer prácticas, hacer voluntariado en $<$ nombre propio > Cruz Roja </nombre propio>, siempre te puede salir algo, o sea que no es cuestión de estar parado aunque no ganes dinero siempre puedes hacer algo y siempre puedes pues aumentar tu <extranjero > curriculum </extranjero> sin necesidad de estar estudiando otra carrera que, lo veo muy bien, y más, yo pienso hacerlo, pienso.......] (Azorín y Jiménez, 1999: 123).

(26) $317<E 2>$ : [...] en esta sociedad, si quieres que te escuchen tienes que ser una multitud, si no, no te escuchan... si son varios pues ya se lo piensan (Azorín y Jiménez, 1999: 201).

(27) $<B 2, H, 3, B a, E I, E>$ : [...] pero que a veces todo esto lo ves piensas y piensas también que hay padres en situación de decir: "quiero tener un hijo", pero es que veo, es un problema que hay que verlo, el decir: [...] (ALCORE, pág. 1095).

Según algunos autores — Ma Lluïsa Hernanz (Hernanz, 1990a: 171-173), Fernández Soriano y Táboas Baylín (Fernández y Táboas, 1999: 1736-1737) - , cuando estos constituyentes adverbiales se sitúan en su posición habitual, normalmente, la segunda persona recupera su contenido referencial. Ello se debe, en opinión de Hernanz, a que, cuando se posponen al sintagma verbal, estos elementos de carácter adverbial se originan dentro del sintagma verbal y lo modifican. La segunda persona del singular, en tales casos, quedaría al margen de la posible influencia que estos elementos puedan ejercer. Sin embargo, en posición dis- 
locada, ya no modifican al verbo únicamente, sino a toda la oración y la segunda persona se encuentra también dentro del ámbito en el que operan. Esta es una de las razones por las que $\mathrm{M}^{2}$ Lluïsa Hernanz considera que la segunda persona del singular se comporta como una variable. Por tanto, estos elementos ofrecen un marco temporal y espacial indeterminado en el que el hablante sitúa un enunciado de carácter universal.

No obstante, no debemos soslayar, que si bien la tematización de estos componentes adverbiales contribuye en gran medida a la generalización de la segunda persona del singular, esa misma genericidad la podemos encontrar también, dependiendo del contexto, cuando ocupan su posición habitual, aunque ya no tendrían un carácter tan marcado. Incluso, podemos encontrar determinados elementos adverbiales temporales que aluden a un momento concreto en el tiempo y, sin embargo, con ellos también podemos obtener una lectura generalizada:

(28) $\langle T 5, H, 2, B a, E I, V>$ : Antes mucho mejor, antes ibas tranquilo por la calle, no se metía nadie contigo, ni nada, ¿pero hoy? Hoy te tienes que<pausa $></ p a u s a>$ $<$ repetición $>$ te tienes que $</$ repetición $\rangle$, que ir mirando pa $\langle($ ra $)\rangle\langle(a)\rangle$ trás y pa $<($ ra $)><(d e)>$ lante por si te cogen. Y es verdad (ALCORE, pág. 281).

(29) $<T 1, M, 3, S u, E E, E>$ : [...] Ahora no, ahora te dan de baja en Navidades esos días, $<$ repetición>esos dias</repetición> no se cobran y te dan de alta otra vez en enero [...] (ALCORE, pág. 340).

En cuanto a las estructuras sintácticas con valor condicional, debemos resaltar la forma de condicional lógico si....entonces.... Se trata siempre de dos proposiciones relacionadas mediante estos dos tipos de conectores, aunque es frecuente la elisión del segundo conector entonces ${ }^{4}$ :

(30) $419<H 7>$ : Es que lo que dice la gente que (-->)... bueno, en los anuncios de tráfico que... pero se puede... adecuar a esto también, que las consecuencias no sólo las pagas tú, porque (-->) <vacilación> no destrozas sólo a una vida, destrozas muchas vidas al tener que estar dependiendo de... de dinero y de... de muchas situaciones que, si no estuvieses en droga, [entonces] no estarias ahi metido [...] (Azorín y Jiménez, 1999: 122).

(31) <Chu8,H,2,Me,EE,E>: [...] Yo veo a mi hijo, <repetición>a mi hijo</repetición >, a Angelito. Si no se <palabra cortada>po</palabra cortada>, si no le compras unas Nike [entonces] no se las pone. Y tiene que ser Nike (ALCORE, pág. 210).

(32) $<<C h u 6, M, 2, S u, E E, E>$ : [...] que si no consigues esas <sic >mesas $</$ sic $>$, metas, [entonces] es como si fueras $u n,<$ repetición $>$ un $</$ repetición $>$ fracasa $<(d)>0$, ¿no? [...] (ALCORE, pág. 210).

(33) $348<H 4>$ : Dispuesto a contarle a tu madre <estilo directo> pues, mira, me ha deja $<($ d $)>0$ la novia $(->) \ldots$ simultáneo $>$ y $(->) \ldots$ pasa tal $<$ ininteligible $></$ si- 
multáneo $><$ estilo directo $>$ o si eres más reserva $<(d)>0$, pues te lo callas y tú mismo te vas, te vas currando la cabeza, ¿sabes? <vacilación>Va, depende de la naturaleza de la persona, o sea, no puedes generalizar (Azorín y Jiménez, 1999: 73).

(34) $462<$ E2>: ;Hombre!, es segura (-->) si tu rela <palabra cortada $>$ si ti tienes relaciones habitualmente con esa pareja y e <palabra cortada $>$ esa pareja contigo, simplemente. Está claro que si tú te vas acostando por ahi con un montón de tias y luego vienes a mi y te acuestas conmigo, pues que tengo más posibilidades de cogerlo (Azorín y Jiménez, 1999: 128).

Como podemos comprobar, el segundo conector que enlaza la segunda proposición que expresa la consecuencia de la condición representada por la primera proposición, aparece frecuentemente elidido. También es posible la presencia del elemento pues en lugar de entonces tal como se muestra en los dos últimos ejemplos. Esto se debe a que cuando entre la prótasis y la apódosis existe una relación de condición-consecuencia, ambos elementos son intercambiables (Montolío, 1999: 1715).

Además de la forma de condicional lógico representada por los conectores si y entonces, hay una serie de locuciones o expresiones con valor condicional (siempre que, a no ser que, con tal que, mientras que, etc.) y concesivo (por mucho que) que pueden actuar como "operadores genéricos" en las estructuras de los singulares arbitrarios. Algunas de ellas las hemos encontrado en nuestros corpora, junto con otras de valor temporal (una vez que) y concesivo-condicional universal (te venga lo que te venga) que a nuestro juicio funcionan también como "transmisores de genericidad" (Fernández y Táboas, 1999: 1735):

(35) $417<H 4>$ : Yo creo... yo creo que es todo psicológico.. es todo (-->) si tú sabes lo que haces hasta el momento siempre que lo controles puedes fumar to $\langle(d)\rangle\langle(0)\rangle$ lo que quieras, pero siempre tienes que saber donde estás [...] (Azorín y Jiménez, 1999: 148).

(36) $420<H 3\rangle$ : Hombre, una vez que (-->) estás drogado a lo mejor puede inftuir lo que te puedas meter.. o no... (Azorín y Jiménez, 1999: 148).

(37) $795<H 5>$ : Hombre, al principio te choca, te choca ¿eh?, y por mucho que intentes, yo tampoco dejaría de ir con él y me chocaría muchísimo, pero no lo miras con los mismos ojos. Aunque tú, aunque tú quieras tal y cual, tal y cual, pero no lo miras con los mismos ojos (Azorín y Jiménez, 1999: 163).

(38) $272<H 2>$ : [...] salir del sistema no vas a poder salir nunca, porque estás metido en él, está claro, a no ser que te vayas a una isla, tú solo que no te lo recomiendo $<$ risas> a no ser que seas muy fuerte de espiritu, pero bueno, y pienso <palabra cortada $>q u<(e)>$ es que, nosotros somos los que tenemos que crear nuestra propia personalidad y decir, no [...] (Azorín y Jiménez, 1999: 199).

(39) $45 I<H 2>$ : Hombre, mientras que no sea que lo hagas todos los sábados (Azorín y Jiménez, 1999: 209).

(40) $318<E I>$ : Pero eres un profesional $</$ simultáneo $>$ y a ti te pagan por eso $<$ simultáneo $>$ entonces... entonces te venga lo que te venga tienes que hacer... (Azorín y Jiménez, 1999: 273). 
En este apartado nuestro objetivo ha sido demostrar que el uso arbitrario de la segunda persona del singular obedece, en muchas ocasiones, a factores de índole temporal y aspectual reforzados mediante la actuación de determinados elementos sintácticos presentes en el entorno oracional, siguiendo el planteamiento de M. Luïsa Hernanz. En este sentido, además del uso del pronombre $t u ́$, junto con su desinencia verbal correspondiente, se requiere la presencia de toda una serie de operadores que contribuyen a que la estructura oracional reúna las condiciones necesarias para la interpretación universal pretendida.

Sin embargo, debemos señalar que la sola presencia de esta serie de operadores genéricos no es la única razón que debe llevarnos a hablar de arbitrariedad, dado que estos mismos operadores, en enunciados que no sean genéricos, no facilitarían ningún tipo de interpretación universal. Este aspecto puede ser contemplado a través de una serie de ejemplos no extraídos de ningún corpus, sino procedentes de nuestra propia invención con los que se pretende demostrar que sin un contexto genérico, el uso de la segunda persona del singular es completamente referencial:

\section{(41) Puedes venir conmigo esta noche si quieres}

(42) Tienes que ir al médico sin falta esta semana

(43) No te preocupes por este pequeño fracaso, siempre puedes volver a empezar

(44) Si vienes conmigo, entonces te daré una sorpresa

(45) Ya sabes que siempre que quieras, puedes venir a mi casa

(46) A no ser que tengas algo que hacer esta noche, podrias venirte conmigo a cenar

Desde nuestro punto de vista, estos ejemplos nos ayudarían a confirmar el hecho de que estos operadores por sí mismos no expresan genericidad ni inducen a ella, sino que para que puedan reforzar esa lectura impersonal del $t u ́$ deben ser utilizados en contextos genéricos.

En este sentido, nos quedaría responder a un último interrogante que consiste en averiguar por qué la presencia de estos elementos en el entorno oracional de la segunda persona de singular subrayan la arbitrariedad de la misma —en contextos genéricos-. Este interrogante intentará encontrar su respuesta en el siguiente apartado.

\section{La modalidad lingüística y los singulares arbitrarios}

La modalidad lingüística opera en dos niveles fundamentales: en el nivel del enunciado y en el nivel de la enunciación. En el nivel del enunciado, recoge la actitud del hablante con respecto a la verdad del contenido de la proposición que formula (si se trata de un enunciado posible, imposible, etc.). En el nivel de la enunciación, atiende al acto de comunicación en sí y a la manera como el hablante formula cada uno de sus enunciados, es decir, si responde a un mandato, una pregunta, una afirmación, un deseo, etc.

Nuestra hipótesis de partida es que buena parte de los recursos que hemos mencionado en el apartado anterior y que hemos analizado como responsables, en parte, del valor genérico y no referencial de la segunda persona de singular, están estrechamente vinculados a la 
categoría lingüística de la modalidad. Hay dos tipos de modalidad: la modalidad epistémica, ligada a las nociones de creencia y de conocimiento y la modalidad deóntica, unida a las nociones de mandato, obligación o deseo. En nuestros ejemplos hemos encontrado muestras de ambos tipos de modalidad.

Comenzaremos primeramente con la modalidad epistémica, pues es la que más predomina en el tema que nos ocupa: los singulares arbitrarios. Según E. Ridruejo (1999: 3214), la modalidad epistémica se expresa en español mediante adverbios, adjetivos, verbos modales y la variación en el modo del verbo. Un ejemplo de esa variación modal sería el siguiente:

(47) $\langle$ Chu6, M,2,Su,EE,E>: De todas maneras $</$ simultáneo $>$, también pienso yo que a veces a los jóvenes se les $<$ pausa $></ p a u s a><$ repetición $>$ se les $</$ repetición $>$ planteaunas $<$ pausa $></$ pausa $><$ repetición $>$ unas $</$ repetición $>$ metas $<$ fático $></$ fático $><$ pausa $></$ pausa $>$ a conseguir, que si no consigues esas $<$ sic $>$ mesas $</$ sic $>$, metas, es como si fueras un, <repetición $>$ un $<$ /repetición $>$ fracasa $<(d)>0$, ¿no? $[\ldots]$ (ALCORE, pág. 210).

En este ejemplo se produce una variación del modo verbal (de indicativo a subjuntivo). Hemos pasado de un mundo real a un mundo posible, esto es, de un mundo en el que la juventud debe cumplir con unas expectativas a un mundo en el que podría llegar a considerarse como un fracaso el incumplimiento de esos objetivos. El punto de vista del hablante se encuadra dentro de la modalidad epistémica, dado que, según su parecer y su conocimiento del mundo, existe la posibilidad de que si la juventud no alcanza los objetivos que se marca en la vida, podría llegar a ser considerado un fracasado. Además de la implicación pragmática que existe entre ambas proposiciones (no conseguir las metas que uno se propone en la vida es igual a fracaso), debemos tener en cuenta que el hablante sitúa su enunciado con respecto a su valor de verdad. En este caso, podría tratarse de un enunciado posible, con lo que la modalidad operaría en el nivel del enunciado.

Sin embargo, como hemos comentado anteriormente, el hablante se distancia constantemente de su enunciado, no desea responsabilizarse o comprometerse con lo que está diciendo. De ahí que se sirva de todos los recursos que tiene a su alcance para formular un enunciado de carácter hipotético y utilice la segunda persona de singular para ocultarse a sí mismo.

Los verbos modales también constituyen, como señalábamos, un ejemplo de modalidad epistémica, aunque, como veremos más adelante, también pueden ser ejemplo de modalidad deóntica. En nuestro corpus, el verbo modal predominante con el sentido de posibilidad es poder:

(48) $265<H 4>$ : [...] Entonces, ya más o menos, te ven, te ven la tendencia o lo que tú puedes hacer bien y lo que no puedes hacer bien [...] (Azorín y Jiménez, 1999: 66).

(49) $466<H 7>$ : Es la barre <palabra cortada>... es la barrera más efectiva, pero no tienes una total segurida $\langle(d)>$, entonces tú a tu pareja le puedes decir que si, que (-->) siempre que has tenido relaciones sexuales... <fático $=$ duda $>$ has usado el preservativo, [...] (Azorín y Jiménez, 1999: 128). 
(50) $420<H 3>$ : Hombre, una vez que (->) estás drogado a lo mejor puede influir lo que te puedas meter... o no... (Azorín y Jiménez, 1999: 148).

(51) $428<H 7>:[\ldots]$ Puedes meterte si quieres a hacer prácticas (-->)... <vacilación $>$... a hacer prácticas, hacer voluntariado en <nombre propio> Cruz Roja <inombre propio $>$, siempre te puede salir algo, o sea que no es cuestión de estar parado aunque no ganes dinero siempre puedes hacer algo y siempre puedes pues aumentar tu <extranjero > curriculum <lextranjero> sin necesidad de estar estudiando otra carrera que, lo veo muy bien, y más, yo pienso hacerlo, pienso.. [...]. (Azorín y Jiménez, 1999: 123).

Con estos enunciados, el hablante pone de manifiesto su actitud subjetiva ante la probabilidad de cumplimiento de los acontecimientos denotados a través del verbo modal poder. Es su creencia, basada de nuevo en su conocimiento del mundo, la que sobresale en estos ejemplos.

Antes de pasar a comentar algún ejemplo de la modalidad deóntica, es interesante que veamos cómo se desarrolla la modalidad epistémica en las oraciones condicionales presentes en nuestro análisis de los singulares arbitrarios. Para no extendernos demasiado en esta cuestión, comentaremos únicamente los casos más interesantes.

En primer lugar, hemos encontrado ejemplos de condicionales reales en las que el modo verbal tanto en la prótasis como en la apódosis es el presente de indicativo:

(52) $341<E 2>$ : [...] por ejemplo, yo me llevo bien con mi madre y todo esto pero $(-->)$.. que, normalmente cuando tienes un problema o lo que sea, que no sueles recurrir a los padres... y todo esto (Azorín y Jiménez, 1999: 72).

(53) $317<E 2>:[\ldots]$ en esta sociedad, si quieres que te escuchen tienes que ser una multitud, si no, no te escuchan... si son varios pues ya se lo piensan (Azorin y Jiménez, 1999: 201).

El primer ejemplo constituye una oración condicional real formada por dos proposiciones que expresan acciones habituales, reiteradas o verdades omnitemporales, es decir, el hablante considera, en virtud de su conocimiento del mundo y de sus experiencias personales, que siempre ocurre así. En estos casos, el nexo condicional si, suele equivaler a cuando, como vemos en nuestro ejemplo.

En el segundo caso, sin embargo, a pesar de que encontramos el presente de indicativo en ambas cláusulas, la forma verbal que encontramos en la apódosis, que suele ser un verbo modal, está orientada hacia el futuro. En la subordinada condicional se expresa una acción que se corresponde con el momento de la enunciación y da lugar a otra acción que se proyecta sobre el futuro (Si quieres que te escuchen, tendrás que ser una multitud). Esta misma idea podemos aplicarla a otros ejemplos en los que, si bien sigue apareciendo el presente de indicativo en la prótasis, la forma verbal que aparece en la apódosis es condicional:

(54) $441<H I>$ : Pues nada, eso, yo pienso que si construyes un mundo no habria clases sociales pero que las hay, y ya está, y que tanto clases sociales como (->) no igualda $\langle(d)\rangle$ de oportunidades ni como eso, [...] (Azorín y Jiménez, 1999: 98). 
Según E. Montolío (1999: 3665), el uso del condicional supone un distanciamiento del hablante con respecto a su enunciado. Por otro lado, si bien señala que este tipo de estructura suele ser característica del lenguaje periodístico, también es frecuente en los corpus orales "con valores modales de diferentes grados de expectabilidad".

No obstante, no sólo hemos encontrado ejemplos de condicionales reales, sino también de condicionales irreales, en las que ya apreciamos la presencia del subjuntivo en la prótasis:

(55) $419<H 7>:$ : [..] si no estuvieses en droga, no estarias ahi metido (Azorín y Jiménez, 1999: 122).

(56) $417<H 4>$ : Yo creo... yo creo que es todo psicológico.. es todo (-->) si tú sabes lo que haces hasta el momento siempre que lo controles puedes fimar to $\langle(d)\rangle\langle(o)\rangle$ lo que quieras, pero siempre tienes que saber donde estás (Azorín y Jiménez, 1999: 148).

(57) $272<H 2>$ : [...] salir del sistema no vas a poder salir nunca, porque estás metido en él, está claro, a no ser que te vayas a una isla, tú solo que no te lo recomiendo $<$ risas> a no ser que seas muy fuerte de espiritu, pero bueno, [...] (Azorín y Jiménez, 1999: 199).

(58) $451<H 2>$ : Hombre, mientras que no sea que lo hagas todos los sábados (Azorín y Jiménez, 1999: 209).

En el primer caso, la presencia del imperfecto de subjuntivo implica la descripción y situación de unos hechos en un mundo posible o hipotético. Con este tipo de estructura condicional, el hablante está dando a conocer su falta de seguridad ante la realización de la acción y la presenta como poco probable, aunque no imposible. A pesar de que se ha subrayado el hecho de que, cuando estas estructuras condicionales de imperfecto de subjuntivo más condicional tienen valor contingente, las dos formas verbales aluden a momentos futuros; en el caso que nos ocupa, al usarse la segunda persona del singular con valor genérico, no podemos aplicar dicha hipótesis. El enunciado que estamos analizando responde más bien a una creencia generalizada por parte del hablante que puede encuadrarse en cualquier momento temporal. En los ejemplos restantes, la combinación de locuciones prepositivas con valor condicional más subjuntivo, sitúa de nuevo a los enunciados en el mundo de la posibilidad.

Como vemos, la modalidad epistémica es, sin duda, la más frecuente en los contextos propios de los singulares arbitrarios. Esto no nos debe extrañar si tenemos en cuenta que el hablante a través de la segunda persona se oculta a sí mismo para evitar que se le identifique con lo que esta diciendo, de la misma manera que la modalidad epistémica se centra en esa falta de compromiso por parte del emisor con respecto al valor de verdad que pueden presentar sus enunciados.

Sin embargo, como adelantábamos anteriormente, la modalidad epistémica no es la única presente en el uso del tú como impersonal. También hemos encontrado indicios de modalidad deóntica, expresada especialmente, a través de verbos modales vinculados a la noción de obligación: 
(59) $\langle P 14, H, 3$, Me,EI,E $>$ : Nosotros hemos ido a Valencia y hemos estado en Valencia hace muy poco y alli todo el mundo hablaba castellano; no hay nadie que hable en $<$ ininteligible></ininteligible> te tienes que ir a Alzira, te tienes que ir a yo que sé (ALCORE, pág. 757).

(60) $208<H 4>$ : Lo hace, lo hace mucha gente $</$ simultáneo $\rangle$, sobre todo al llegar en verano la <vacilación $>$... <nombre propio $>$ San Juan $</$ nombre propio $>$... y todo $<(s)>$ estos sitios $<$ fático $=d u d a>$ te, te vendes; o sea, tienes que estar trabajando nueve, diez, once horas al dia y te <simultáneo> dan cuarenta mi (Azorín y Jiménez, 1999: 64).

(61) $317<E 2>$ : [...] en esta sociedad, si quieres que te escuchen tienes que ser una multitud, si no, no te escuchan... si son varios pues ya se lo piensan (Azorín y Jiménez, 1999: 201).

En este apartado hemos intentando, aunque de forma muy breve, vincular los singulares arbitrarios a la categoría de la modalidad. Con ello, hemos pretendido demostrar que no sólo la presencia de determinados elementos lingüísticos es la responsable de la arbitrariedad de la segunda persona del singular, sino también el punto de vista del hablante, bien con respecto al valor de verdad del enunciado, bien con respecto al acto de comunicación en sí. Pero sobre todo, no debemos olvidar que la mera presencia de estos elementos lingüísticos no es la única responsable en la obtención de enunciados genéricos, sino que son, en todo momento, el contexto y la situación discursiva la que nos conducen hacia la genericidad y hacia la lectura arreferencial del $t u$.

\section{Conclusiones}

A lo largo de este estudio hemos pretendido poner de manifiesto el abundante uso impersonal de la segunda persona del singular en corpora orales, aunando sus dos vertientes: una, de carácter generalizador, que acogería a una totalidad de individuos y, otra, que se correspondería con un encubrimiento pragmático del yo hablante, el cual se distancia del enunciado para no ser responsable de su propio discurso. Esta versatilidad del pronombre de segunda persona constituye, indudablemente, la nota más sobresaliente de estas estructuras. No obstante, como hemos podido comprobar, el sentido genérico y el encubridor del yo van constantemente unidos y no es posible desligarlos. Por ello, nuestros únicos recursos para desarrollar esa labor interpretativa son el contexto y la situación, con lo que es indispensable el papel que juega la pragmática en las construcciones que nos ocupan.

Por otra parte, hemos querido incluir en nuestro estudio las estructuras con sujeto indefinido uno/a para demostrar que este uso impersonal no es exclusivo del pronombre tú, sino que se extiende a otras formas de carácter indefinido que asumen igualmente un contenido referencial generalizador, en el que se oculta el propio hablante, evitando focalizar su individualidad en el discurso.

Sin embargo, el pronombre tú, junto con la desinencia personal que lo identifica, requieren, según Hernanz, la presencia de otros elementos que favorezcan la falta de contenido referencial que experimenta la segunda persona del singular en estas estructuras de índole impersonal. De ahí que hayamos destinado un apartado a la exposición de los 
principales factores que posibilitan la lectura arbitraria del pronombre de segunda persona, destacando, entre ellos, los relativos al tiempo y al aspecto verbal. La ausencia de un marco temporal concreto y la imperfectividad que caracteriza a los singulares arbitrarios supone una universalización de los enunciados que se incluyen en estas construcciones. Estos operadores oracionales precisan a su vez de otros operadores genéricos —verbos modales, elementos adverbiales o locuciones afines y estructuras de valor condicional, concesivo e incluso temporal - que dotan al enunciado de un marco temporal indefinido y genérico.

Nos quedaban, no obstante, algunos interrogantes que resolver: ¿Por qué todos estos elementos pueden considerarse transmisores de genericidad? ¿Existe algo más que contribuya a la creación de contextos universales? ¿Es suficiente la sola aparición de estos elementos para obtener una lectura genérica? Las dos primeras preguntas han encontrado su respuesta en el ámbito de la modalidad lingüística, pues hemos podido apreciar cómo la posición del hablante tanto en relación al enunciado como en relación al acto de enunciación resulta especialmente relevante y determinante en la interpretación generalizadora del tú y en su vertiente encubridora. Por lo que respecta a la pregunta sobre si es suficiente o no la aparición de estos operadores genéricos para encontrarnos ante un enunciado genérico, debemos señalar que el punto de partida siempre debe ser el contexto y la situación comunicativa. Sólo a través de estos fenómenos pragmáticos sabremos si estamos ante un tú referencial o un tú genérico. Una vez que hayamos comprobado que nos encontramos en un contexto genérico, el resto de elementos que aparezcan como inductores genéricos podrán contribuir a la lectura arbitraria de la segunda persona, pero, si lo hacen, es debido, fundamentalmente, a que operan en un marco discursivo que ya ha sido establecido previamente como genérico.

Finalmente, no quisiéramos concluir este estudio sin hacer alusión al tratamiento que realizan nuestras gramáticas del español de los singulares arbitrarios. Según Hidalgo Navarro (Hidalgo, 1996: 166), este uso impersonal del pronombre de segunda persona del singular no se recoge normalmente en las gramáticas del español debido, entre otras razones, a que nuestras gramáticas parecen basarse preferentemente en la lengua escrita, atendiendo en mayor medida al enunciado que a la enunciación. Como excepción a esta tendencia general, este autor menciona a Manuel Seco, quien hace referencia al valor impersonal de tú a propósito de las estructuras con el sujeto indefinido uno/a (Seco, 1994: 251). No obstante, este fenómeno sí que está presente en algunos trabajos de carácter normativo, como el de Gómez Torrego (Gómez, 1992: 13-16), y se ha ido incorporando poco a poco en nuestras gramáticas.

De todas formas, lo cierto es que, si bien este uso de la segunda persona del singular pertenece fundamentalmente al ámbito coloquial, parece lógico pensar - y en esto coincidimos plenamente con Antonio Hidalgo- que será necesario recurrir a textos orales para acceder a este tipo de fenómenos lingüísticos y dar constancia de ellos. Además, si en el estudio de una lengua es tan importante el conocimiento de la lengua escrita como del habla, creemos que en la didáctica del español como lengua extranjera debe incluirse este uso que los hablantes del español realizan del pronombre de segunda persona si queremos que los estudiantes extranjeros mejoren su competencia comunicativa. 


\section{Referencias bibliográficas}

Azorín Fernández, D. y J. L. Jiménez Ruiz (eds.) (1999): Corpus oral de la variedad juvenil universitaria del español hablado en Alicante. Alicante, Instituto de Cultura Juan Gil-Albert.

Azorín Fernández, D. (coord.) (2002): Alicante corpus del español (ALCORE). ISBN: 84-7908-684$\mathrm{X}$.

Briz Gómez, A. (1998): El español coloquial en la conversación. Esbozo de pragmagramática. Barcelona, Ariel Lingüística.

Fernández Soriano, O. y S. Táboas Baylín (1999): "Construcciones impersonales no reflejas". En Bosque, I. y V. Demonte (dirs.): Gramática descriptiva de la lengua española. Madrid, EspasaCalpe, págs. 1723-1778.

Gómez Torrego, L. (1992): La impersonalidad gramatical: descripción y norma. Madrid, Arco/Libros, 1998.

Hernanz, M. L. (1990a): "En torno a los sujetos arbitrarios: la $2^{a}$ persona del singular". En Demonte,

V. y B. Garza Cuarón (eds.): Estudios de lingüística de España y México. México, Universidad Nacional Autónoma de México, págs.151-178.

Hernanz, M. L. (1990b): "Personas generales y tiempo verbal". En Wotjak, G. y A. Veiga (coords.): La descripción del verbo español. Verba, Anuario Galego de Filoloxía, Anexo 32, Santiago de Compostela, Universidade de Santiago de Compostela, págs. 153-162.

Hidalgo Navarro, A. (1996): "Sobre los mecanismos de impersonalización en la conversación coloquial", ELUA, 11, págs. 163-176.

Lorenzo, E. (1989): “Relación interpersonal y expresión impersonal”. En Rodríguez González, F. (ed.): Comunicación y lenguaje juvenil. Madrid, Fundamentos, págs. 217-239.

Montolío, E. (1999): "Las construcciones condicionales". En Bosque, I. y V. Demonte (dirs.): Gramática descriptiva de la lengua española. Madrid, Espasa-Calpe, págs. 3643-3737.

Ridruejo, E. (1999): "Modo y modalidad. El modo en las subordinadas sustantivas". En Bosque, 1. y V. Demonte (dirs.): Gramática descriptiva de la lengua española. Madrid, Espasa-Calpe, págs. 3209-3251.

Seco, M. (1994): Gramática esencial del español. Madrid, Espasa-Calpe.

Vicente Mateu, J. A. (1994): La deixis. Egocentrismo y subjetividad en el lenguaje. Universidad de Murcia, Secretariado de Publicaciones. 